\title{
Á MEMÓRIA DE GERALDO PINHEIRO
}

\author{
The memory of Geraldo Pinheiro
}

\begin{abstract}
Aloysio Nogueira
Nos últimos momentos da tarde de 25 de maio deste ano, quando o sol Amazônico se recolhia lentamente no poente do Rio Negro, alunos, administrativos, professores da Universidade Federal do Amazonas - UFAM, e família Sá Peixoto Pinheiro, consternados, conduziam Geraldo Pantaleão Sá Peixoto Pinheiro ao seu jazigo no Cemitério São João Batista.

Naquele instante, para começar a tecer algumas considerações sobre alguns elementos do início da trajetória intelectual de Geraldo, lembrei-me de que alguém já dissera: "quando se morre, conclui-se apenas mais uma jornada de trabalho; recomeça-se uma nova jornada de trabalho na manhã do dia seguinte do mundo espiritual”.

Geraldo teve a sua primeira jornada de trabalho interrompida prematuramente, aos 66 anos. A jornada de trabalho do seu dia seguinte, agora consubstanciada em sua memória, reproduzir-se-á eternamente não no mundo espiritual, mas nas praxes de todos que concebem a necessidade do desenvolvimento da Ciência da História em todos os campos do saber que lhe é peculiar.

Nesse processo, Geraldo faz parte dos inúmeros alunos e professores que se deram as mãos e corações para se dedicarem diuturnamente à construção da Ciência da História no Amazonas, que em meio século de luta, sobressaem à criação do Curso de Licenciatura Plena de História, em 1981, e do Departamento de História do Instituto de Ciências Humanas e Letras da Universidade do Amazonas, em 1985.

Conheci Geraldo durante as minhas primeiras aulas de História do Brasil na Escola Estadual Márcio Nery, localizada a Rua Prof. Márciano Armond, s/n - São Francisco, em 1967. Esse momento, que coincidiu com o início de minhas atividades profissionais, desenvolveu-se com o processo que envolveu ao longo do tempo, alunos e professores que foram identificados por realizarem movimentos destinados à formação de historiadores no Amazonas. É na consecução desse propósito que a jornada de trabalho de Geraldo se encontra inserida, visto que como aluno de escola de primeiro grau já demonstrara sua dedicação a essa causa.

De fato, Geraldo, ao tomar conhecimento da conjuntura política educacional do Amazonas no que tange a todas as problemáticas que envolviam as condições para a preservação documental,
\end{abstract}


pesquisa, produção e ensino dos acontecimentos históricos, esteve presente de maneira exemplar em todos os momentos, primeiro como aluno e em seguida como professor da UFAM.

Até a década de 60 os professores no Amazonas que lecionavam a disciplina História eram portadores do chamado exame de suficiência, promovido pelo Ministério da Educação. Com a implantação efetiva do curso de filosofia da Universidade do Amazonas - UA, em 1961, abriu-se a possibilidade de se incluir na grade curricular do Curso de Licenciatura em Filosofia, disciplinas da área de História: História das Civilizações e História do Brasil, o que de fato ocorrera a partir de 1967. Neste caso, segundo a legislação, quem estivesse matriculado no curso de filosofia já poderia lecionar no ciclo ginasial tais disciplinas correspondentes. Daí, não bastaria ao aluno se dedicar apenas à reflexão filosófica, mas desenvolver conhecimentos pertinentes à Clio.

Ao me apresentar aos alunos da Escola Estadual Márcio Nery, em 1967, questionado, dirimi qualquer dúvida sobre a minha formação. Embora eu estivesse naquele recinto lecionando História, ainda me encontrava num processo de formação de historiador, reconhecendo também as limitações impostas pela organização da política educacional de então.

O governo da Ditadura Militar diante da forte demanda por professores devidamente qualificados resolveu tentar superar o exame de suficiência e as limitações das Licenciaturas em Filosofia que ofereciam disciplinas da área de História, implantando cursos de Licenciatura Curta. Dentre as quais, destaco a de Estudos sociais, habilitando ao magistério de História, Geografia e Organização Política e Social do Brasil.

Geraldo não titubeou e realizou o curso de Estudos Sociais na Universidade do Amazonas - UA com destaque, em 1981.

Diante da precariedade do curso de Licenciatura Curta em Estudos Sociais, que desde sua criação, ainda na década de 1970, mostrou-se insuficiente para aqueles que propugnavam pela existência de um curso que ajudasse a estudar, produzir e ensinar a ciência da História, de modo que possibilitasse a formação de profissionais com condições de lidar com toda a problemática da historiografia, podendo, inclusive, superar o conhecimento histórico até então praticado, Geraldo, engajou-se nesse processo juntamente com outros companheiros, o que resultou da UA, através da Resolução Nº 003/80, de 14 de agosto de 1980, criar o curso de Licenciatura Plena em História, matutino com 30 (trinta) vagas por ano, a partir de 1981. É preciso ressaltar que dos alunos aprovados no primeiro vestibular, apenas 4 (quatro) concluíram o curso, em 1984. 
Pela circunstância de o Curso de Licenciatura Plena em História ter sido criado vinculado administrativamente ao Departamento de Ciências Sociais do Instituto de Ciências Humanas e Letras - ICHL - abriu-se outra frente reivindicatória. A verdade é que dois campos importantes das ciências humanas, detentores de amplas necessidades materiais, humanas e culturais, sobretudo, não teriam êxitos científicos caso permanecessem administrativamente vinculados. Daí é que de 1981 a 1985, alunos e professores do curso de Licenciatura em História se tornaram os principais sujeitos do movimento reivindicatório pela criação do Departamento de História, o que acabou se realizando ao final de 1985, através da Resolução Nº 013/85 CONSUNI, de 13 de dezembro de 1985. Dos quatro alunos que haviam concluído o Curso de História, dois foram admitidos como professores do curso através de concurso público: Geraldo Sá Peixoto Pinheiro e Francisco Jorge dos Santos. A dedicação desses professores ao Curso de Licenciatura Plena História é incomensurável, haja vista a produção que realizaram no bojo do longo tempo de serviço que dedicaram à UFAM.

Geraldo Pantaleão de Sá Peixoto Pinheiro, por sua experiência acadêmica, visto que como graduado e já atuando como professor no Ensino Básico, se operou como uma espécie de preceptor dos calouros, em 1981. Não só da História, mas também dos da Geografia, que também começavam naquele ano. O seu dinamismo entusiasmava a turma, na medida em que ia se tornando um verdadeiro líder entre os alunos do curso de História. Ele dominava a bibliografia pertinente com muita qualidade: além de indicar livros, fazia circular os seus próprios exemplares, para que os seus colegas "tirassem xerox" e os apontava o caminho das livrarias Nacional e Maíra, e com a sua influência abria "linha de crédito" com o Zé Maria e Dori Carvalho, respectivamente. Em todos os pleitos encampados pelos alunos de História, ele sempre estava à frente do movimento. Aqui dois episódios sobressaem: O movimento do Colegiado do ICHL contrário ao reconhecimento do Curso de História e a Proposta de incorporação do Curso de História pelo Departamento de Filosofia.

Ainda como aluno do curso de História, foi co-autor de um texto organizado pelo professor José Ribamar Bessa Freire, o qual foi publicado no jornal A Crítica, em dezembro de 1984. O referido texto mais tarde foi transformado em livro, A Amazônia Colonial (1616-1798), publicado pela Editora da Universidade do Amazonas, 1987. Depois pela Editora Metro Cúbico, em 1991.

Como docente, engrossou as fileiras dos professores e alunos envolvidos nas lutas pelo Reconhecimento do Curso de História e pela criação do Departamento de História. Ao mesmo tempo, que se empenhou na reformulação da primeira Grade Curricular de História. Todas essas lutas lograram êxitos. Ademais, Geraldo também participou da organização do catálogo 
de jornais Cem Anos de Imprensa no Amazonas (1852-1951), publicado em 1990, pela Editora Humberto Calderaro, em Manaus. E protagonizou, ao trazer a lume o Acervo Documental da CEDEAM (Comissão Especial de Documentação da Amazônia), que se encontrava inativo, sem que pesquisadores e alunos tivessem acesso ao mesmo, depois que a referida Comissão fora desativada. Pressões de alunos e professores foram realizadas junto à Reitoria da UA com objetivo de sensibilizar os gestores da necessidade de se colocar aquele acervo documental à disposição da comunidade acadêmica interessada na pesquisa histórica e similares. Esse pleito também teve êxito, mas para isso se criou um espaço físico próprio para abrigar o acervo em questão. O Reitor Roberto Vieira sugeriu que fosse implantado o Museu Amazônico para abrigar o Acervo Documental da CEDEAM, o qual já existia no organograma da Universidade. Desta maneira, o Acervo da CEDEAM "veio a lume” com a inauguração do Museu Amazônico, já na gestão do Reitor Marcus Barros.

Geraldo, depois de ajudar nas exitosas lutas políticas acadêmicas do Curso de História, foi liberado para fazer o seu curso de Mestrado, em 1988. O seu Projeto de Mestrado foi comutado para a qualidade de Projeto de Doutorado, pelo seu orientador Prof. Dr. Marcos Silva, da Universidade de São Paulo (USP).

Geraldo Pantaleão Sá Peixoto Pinheiro sublinhou de forma simples o que realizou. Consta em seu Currículo Lattes: "Possui graduação em Estudos Sociais” pela Universidade Federal do Amazonas (1981) e graduação em História pela Universidade Federal do Amazonas (1985) e Doutorado em História pela Universidade do Porto, em Portugal (2012), com diploma revalidado no Brasil pelo Conselho Superior de Ensino, Pesquisa e Extensão da Universidade do Estado do Rio de Janeiro (2015). Professor Adjunto (aposentado) da Universidade Federal do Amazonas, onde exerceu as funções administrativas de Diretor do Museu Amazônico (1993-1996), e por vários biênios Chefe do Departamento e Coordenador do Curso de História, além de ter presidido as diversas reformas curriculares do Curso de História da Universidade Federal do Amazonas. Tem experiências docentes em diferentes áreas do ensino da História; atividades de pesquisa com temas ligados à História da Amazônia, Historia Indígena, História da Imprensa e do Periodismo no Brasil, História e Historiografia Afro-brasileira, dentre outros. Atualmente integra o quadro de pesquisadores do Laboratório de História da Imprensa no Amazonas (DH-UFAM), investigador do CITCEM das Universidades do Minho e do Porto em Portugal e membro do Conselho Científico do Museu da Emigração-Portugal."

Quero registrar aqui as importantes contribuições do ilustre Professor Doutor Francisco Jorge dos Santos neste resumo sobre a Memória de Geraldo Pantaleão Sá Peixoto Pinheiro que, 
além de meu aluno por três vezes, tornou-se meu colega de jornadas de trabalho nesta Instituição que tem historicamente marcado a sua face de qualidade revelada na defesa da Educação Pública, Laica, Gratuita, Democrática, de Qualidade referenciada na sociedade, bandeira fundamental de luta da Associação dos Docentes da Universidade Federal do Amazonas - ADUA, importante lugar que Geraldo também referenciou.

Enfim, urge a necessidade de o Departamento de História escrever a sua própria história, ir muito além das preciosas anotações existentes na produção de seus documentos oficiais. E preciso registrar criticamente as contribuições dos que produziram esse monumento do saber Departamento de História da Universidade Federal do Amazonas.

Obrigado, Geraldo, pela sua primeira jornada de trabalho que infelizmente se encerrou extemporaneamente. Quanto à Segunda, por ser a sua memória infinita, certamente será enriquecida por novas interpretações que superarão este simples resumo. 